\title{
Learning from Slussen: Place, idea and process in the transformation of central urban interstices
}

\author{
Álvaro Clua \\ Laboratori d'Urbanisme de Barcelona, Escola Tècnica Superior d'Arquitectura de Barcelona, \\ UPC. Barcelona, Spain \\ E-mail: alvaro.clua@upc.edu
}

\begin{abstract}
Research Over the last two decades the Slussen in Stockholm designed by Tage William-Olsson in 1935 has been the subject of an intense debate about how to update it to the contemporary needs. Tabula rasa reconstruction or renovation? This lively discussion, however, has resulted in a final proposal granted by the expertise of an international firm but controversial for its political management, opposed to several social groups and, above all, highly problematic in terms of urban form and sustainability. The strategic location of this place, the indelible presence of its modern shape in the collective imaginary or the overwhelming force of the new paradigms of public space, have ended up provoking a range of more than twenty-five proposals in a short period of time. But while today this process seems to be settled and the demolition works of the original structure has already started, it would be still useful to draw some conclusions relevant to other similar interstitial sites in European compact cities where architecture, infrastructure, public space and landscape meet in such an intense way. Thus, this paper summarizes some of the last arguments of the on-going doctoral thesis about the recent evolution of Slussen according to four different outstanding topics: the form of place and history as an undeniable premise; the strength of tactics versus the power of the image in the process; the importance of time in the sequence of urban decision-making and, finally, the weight of urban culture as a key argument in contemporary urban transformation processes.
\end{abstract}

Keywords: Slussen, Urban project, Public space, Infrastructure, Urban culture

\section{Introduction $^{1}$}

Over the last two decades the Slussen in Stockholm designed by Tage WilliamOlsson in 1935 has been the subject of an intense discussion about how to update it to the contemporary needs. Tabula rasa, reconstruction or renovation? The strategic location of this place, the indelible presence of its modern shape in the collective imaginary or the overwhelming force of the new claim for public space has led to the development of more than twenty-five proposals in a short period of time.

However, since 2008 this lively discussion has resulted in a final proposal granted by the expertise of Foster+Partners international firm (Figure 1). Despite some important amendments to the original project carried out by the Stadsbyggnadskontoret of Stockholm, the resolution has been very controversial not only because of the lack of transparency in the political management or the disregard towards the alternatives presented by a number of social and cultural entities, but also because of the highly problematic issues in terms of urban form and environmental impact. The low care towards the conditions of the place, the difficult situation of the bus-terminal under Katarinaberget, the long north-facing staircase 

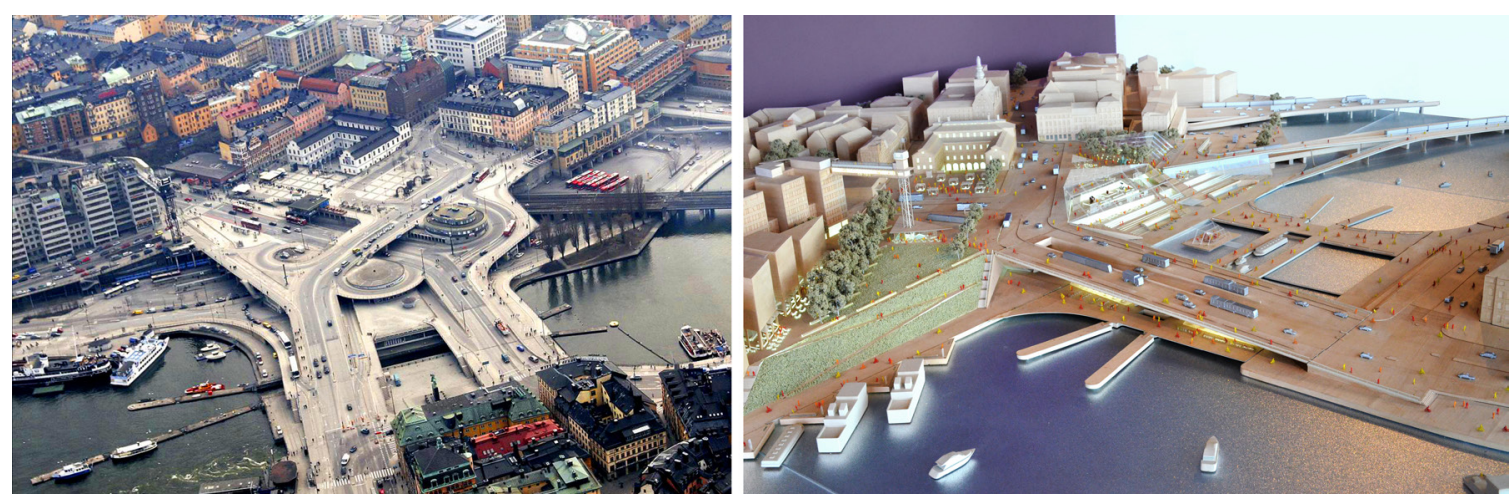

Figure 1. View of the Slussen in 2015 and model of the 'new Slussen' designed on the basis of the proposal by Foster+Partners and Berg Arkitektkontor adopted in the international competition in 2008. Photo by Patrick Sörquist (left) and photo by the author (right), 2016.

with a "transparent" building or the strong segregation between the eight-lane road traffic and the 'water-square' around the lock has been some of the most criticized points by the public opinion ${ }^{2}$.

However, although this proposal has been pushed forward and the structure of the Slussen in 1935 has already been under demolition since 2015, this example might be relevant to draw general lessons on the space, the ideas and the processes that might shape other similar examples. This paper aims to give some arguments to those European central urban interstices of intermediate size -less than 5 hawhere architecture, infrastructure, public space and landscape meet in an intense way, places that are in friction with the central part of the city and, therefore, spaces that coexist and are present in the everyday life and in the common imaginary of citizens.

The importance of addressing those interstitial places in the European context has been widely confirmed by a number of recent researches and practices. Firstly, it is worth mentioning the line of research on Barcelona Links conducted by the Laboratori d'Urbanisme de Barcelona since 2010 and which has already published in two exhibitions (COAC, 2013; CCCB, 2015) and a monograph (Parcerisa and Crosas, 2013). The aim of this approach has been the discussion of new design strategies for several "internal barriers" within the metropolis of Barcelona. Mobility infrastructures, open space opportunities, social disintegration or regulatory gaps has been some of the elements addressed in these places. Other similar researches have been recently carried out by Institut pour la Ville en Mouvement (IVM) / PSA Peugeot Citroën and focused on the conceptualization of Passages as links, places and transitions between different social groups. This approach has produced interesting international competitions and a complete exhibition on this topic (Paris, 2016). Finally, it is worth mentioning other European research experiences in cities like Copenhaguen -with the edition of Transitions. Space in the dispersed city (Juel-Christiansen, 2000); Paris -in the wide spectrum of ideas around the Boulevard Phériphérique by TVK and Tomato Architects; or Antwerp -specially in relation to the Structure Plan by B. Secchi and P. Viganò (2003-2007).

In this framework, which arguments about urban form and decision-making process should we then learn from the Slussen's life and could be applied in the transformation of other similar central urban interstices?

\section{First lesson: interstitial space, activities and dynamics as indelible attributes}

The Slussen (lock) is a strategic place located between Gamla Stan and Södermalm, and connecting Lake Mälaren and Saltsjö (Baltic Sea). From the early times of Stockholm, this complex and steep place has been used as a key strategic gate, as a bastion, customs and lock (Sörenson, 2004: 22-57), as an esplanade for business and wholesale, as a node for public and private transport and as an active urban 
space. All in all, as we have been arguing in our recent doctoral dissertation, the complexity of those spaces similar to the Slussen might be understood as the consequence of the so-called 'interstitial condition', i.e., a set of precise spatial, programmatic and temporal attributes that configure their unique urban form in four different grades: 1 . the place itself; 2 . the projects of 'urban articulation' which seeks to design urban continuity at that point; 3 . the relationship between other similar spaces in the city; 4 . the way those spaces evolve over time. If we focus on the first of those assumptions, it could be said that this 'interstitial condition' might be the combination of three different lenses: the space, the temporal dynamics and the kind of activities that are produced there:

\section{a. Three spatial dimensions of urban interstices}

The spatial configuration of central urban interstices could be defined according to three different intertwined elements: force-vectors, centres of gravity and scene. The force-vectors are the minimum number of lines that shape the basic structure of the place and they could be summarized in, at least, two major ones: the vector that links the opposing pieces and the vector that follows the transverse direction. While the former refers to the urban continuity between different parts of the city, the second is more linked to the systemic urban configuration, i.e., the connection to other interstices, infrastructures or open spaces.

In the Slussen area, the value and presence of the 'earth-vector' and the 'water-vector' has been changing in time (Figure 2). The first

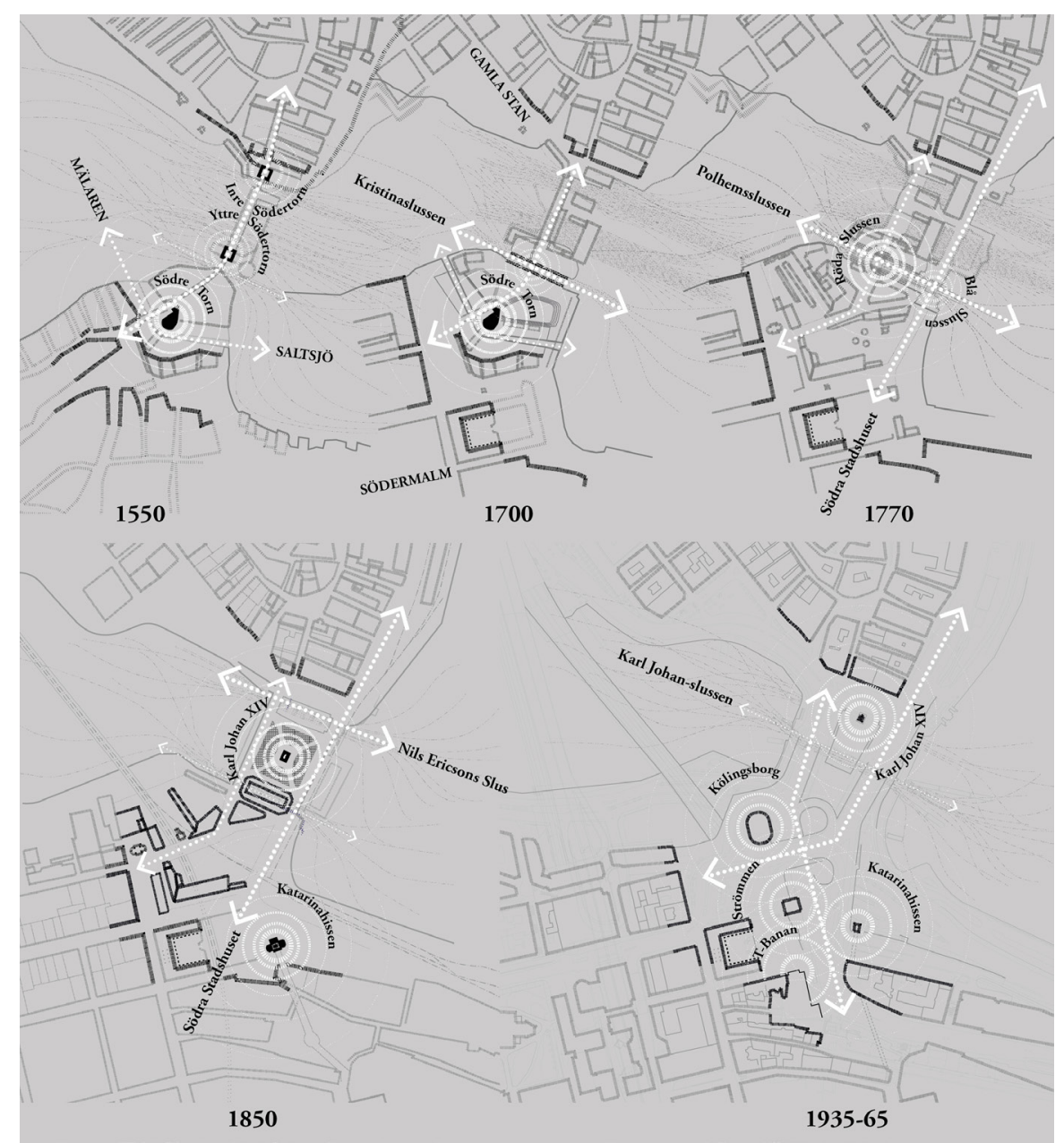

Figure 2. Force-vectors, centres of gravity and urban scene in five different stages of the history of the Slussen, Stockholm: 1550, 1700, 1770, 1850 and 1935-65. Created by the author, 2017. 
centuries of this place were mainly focused around the first one because of its condition as a city gate and customs for the city "mellan broarna" or 'between bridges' (Söderlund and Hjulhammar, 2007). However, with the inauguration of the Kristinaslussen lock in 1642 (Abrahamsson, 2004: 22), the Slussen included a new perpendicular force in the balance of this place. As many engravings shows, for many years the area became a strategic and often conflictive intersection of people, goods and maritime traffic: an urban centre without a clear urban form.

With the turn of the 20th Century and the definitive diversion of the main maritime routes to Hammarby (south of Södermalm) as approved on 25th May 1914, the 'earth-vector' became the key argument in all the upcoming proposals. More than thirty different designs were developed since 1894 in order to display a clear solution for the overall architectonic composition and to provide good integration for an increasing number of horse-drawn carriages, cars, railways, boats, tramways, pedestrians, cyclists and, lastly, the metro system. But both in the drawings presented by Ferdinand Boberg, Carl Bergsten, Ture Ryberg, Per Olof Hallman, Lars Israel Wahlman, or in the final proposal by Tage William-Olsson and Gösta Lundborg, the 'water vector' remained the main argument. This imbalance was clearly modified eighty-five years later, with the undertaking of the renewal and transformation process that started in 1991.

The second element that shapes the spatial configuration of interstitial spaces are the socalled centres of gravity, i.e., those massive or light presences located at the confluence area of the abovementioned vectors to signify and organize these places. They could be seen as an interpretation at a more local scale of the nodes used by the well-known work of K. Lynch and D. Appleyard (1960), or also the concept of ties as stated in the recent $\mathrm{PhD}$ thesis by A. Abraham (2009). The centres of gravity work as fixed points within those dynamic spaces and their position, size and character change as a conscious or unconscious consequence of the balance of the force-vectors. It might be argued that when those centres do not exist, the place is able to generate them but, if it does not succeed, they become informal and mere transient spaces. It could be then stated that the lack of identity of these places is also intimately linked to the absence of precise and meaningful centres of gravity.

These logics may be observed also in the Slussen area, where the centres of gravity were also modified over time: Södretorn until the middle of the XVIII Century; the Södra Stadshuset by N. Tessin (built in 1663 and more active in the spatial configuration after 1935); the sequences of locks (Kristinaslussen in 1642, Polhem Sluss in 1755 and Nils Ericson Slussen in 1852); the sculpture and square around Karl Johan XIV (since 1854); the Katarina lift (1881 and rebuild in 1932) or, finally, the line defined by Kolingsborg(1954), Strömmen Restaurant (since 1936) and the exit of the T-Banan. In the project by Foster+Partners developed since 2008 it remains uncertain which will happen to be the new centre of gravity of this area.

If we focus briefly on other central urban interstices in $\mathrm{E}$ uropean cities, we could draw a similar pattern. Most of them began as spaces occupied by city walls and gates $^{3}$ : Schottenpassage on Schottentor and Opernpassage under Kärntnertor in Wien, Stachuspassage by Karlstor in Münich, Avinguda de la Llum-Plaça Catalunya next to Portal de l'Àngel, Moll de la Fusta-Pla de Palau on the Muralla and Portal de Mar in Barcelona, Hofplein with the Delftsche Poort in Rotterdam before 1940, Stadelhofen on the traces of Stadelhoferbastion in Zürich, Alexanderplatz by Königstor and Potsdamer Platz by Potsdamer Tor in Berlin, Stationsplein in Lovaina or Place des Nations Unies by the Medina of Casablanca. In a second phase, the majority of those sites were converted into market and interchange square, thus moving the centre and the force-vectors out of the gate premises. Together with the demolition of the walls, those spaces tried to achieve a greater urban scale by means of sculptures like the Berolina in Alexanderplatz or the Geni Català in Pla de Palau. Finally, after the arrival of the railway and underground systems, those spaces were refocused mainly towards the stations: the new gates of contemporary cities.

The third element that shapes the spatial configuration of interstitial spaces is the so- 
called urban scene. It could be understood as the set of facades that draws and consolidates the geometry of the space. The scene is defined by a void as its main spatial attribute, by a clear visual and sensible connection to the system of open spaces and, thirdly, by the confluence of a number of different architectures and styles. These places are, therefore, precise records of the evolution of the construction of cities.

\section{b. "What time is this place?"}

As a corollary of what has been argued in the last chapter, it might be confirmed that the temporal dynamics in interstitial places are far more accelerated than their surrounding urban context. The urban scenes are rebuilt and reshaped in short time cycles, the forcevectors change their direction or weight and, subsequently, the centres of gravity move, multiply or disappear. These spaces, unlike other hyper-static urban places, are in perpetum mobile and, consequently, should be designed as adaptive and open systems, using the concept largely explained by Richard Sennett.

This vibrato in the configuration of the urban form and activities could be explained as the interaction of four different rhythms (Figure 3): 1. the historical time made of the palimpsest of constructions, street lines and presences defining the space and the future projects (Cfr., Corboz, 2001); 2. the time of ideas manifested in the process of design; 3 . the time of urban resonances or the moment when any particular place establishes relationships with other sites of similar interstitial conditions and shapes the forma urbis (Parcerisa, 2012); 4. the time of use as a stage where the urban articulation project is built, used (Cfr., Lefebvre, 2004) and decay (Lynch, 1990).

If we focus specifically on the second

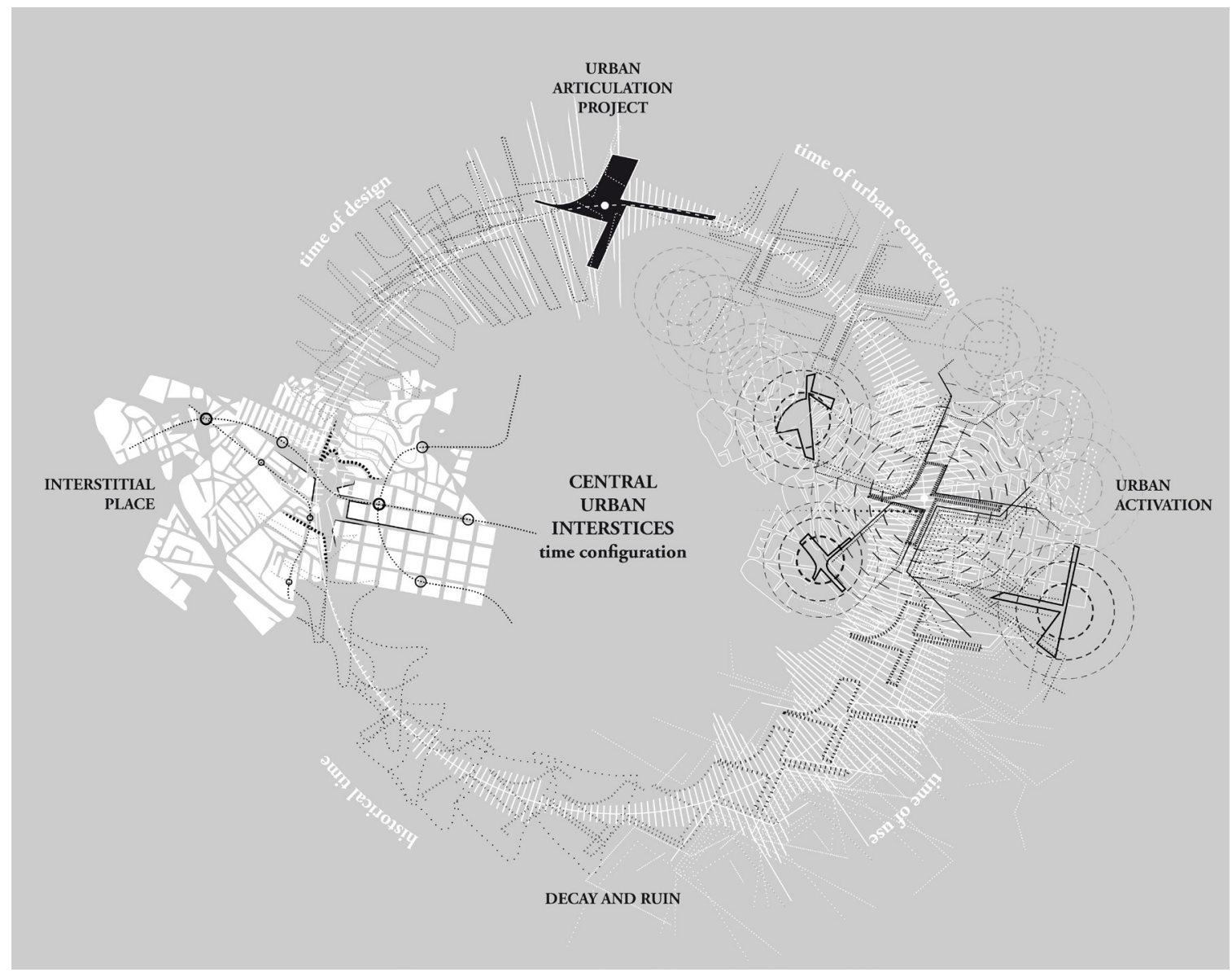

Figure 3. The configuration of central urban interstices as an interaction of four different times: 1 . the historical time; 2 . the time of design; 3 . The time of urban resonances; 4 . the time of use and decay. Created by the author, 2017. 
and third of those times, two different ways of transformation may be pointed out: the aggregative, opportunistic and gradual evolution and, on the other hand, the use of unitary projects like large infrastructures, big competitions or overall masterplan. These are two design logics that come hand by hand in central interstices and express a simultaneous global and local thinking. This double identity has been well described by Carsten JuelChristiansen (1985: 68) with the idea of "doublelocality" as a category of the "new architecture" of the late 20th Century. When applied to the urban scale, this concept alludes to a duality of scale, uses and rhythms. It could be therefore argued that the denial of any of those dimensions in the design of those spaces generates banalization and simplification in their urbanity.

\section{c. In-between activities}

As a consequence of the last argument, it might be well observed that in most of the analysed case-studies, the activities and uses are simultaneously peripheral and central. Peripheral because of their clear peri-urban position in the city and because they often host some urban facilities that have been expelled from the central areas. But at the same time, the activities might be also considered central since their unique position is very strategical for the system of urban routes and because these peripheral facilities are, indeed, essential in the metabolism of the city. The activities held in Slussen and other similar places are indeed "infrastructural" or, in other terms, 'below of' or 'in the service of' the structure. That may explain why most of those transition spaces do not have housing and, conversely, why those are profitable areas to develop varied and mixed commercial activities due to its high accessibility.

\section{Second lesson: modern infrastructure heritage as an operative design tool}

In the same way as the Slussen in Stockholm, most of the central urban interstices are not only defined by their unique spatial configuration, activity and temporality, but also by the active presence of urban heritage in the process of transformation. By the term 'heritage' we would like to refer both to the built constructions as well as those unbuilt projects or ideas that have been drawing the site year after year and constitutes a solid background (Figure 4). This

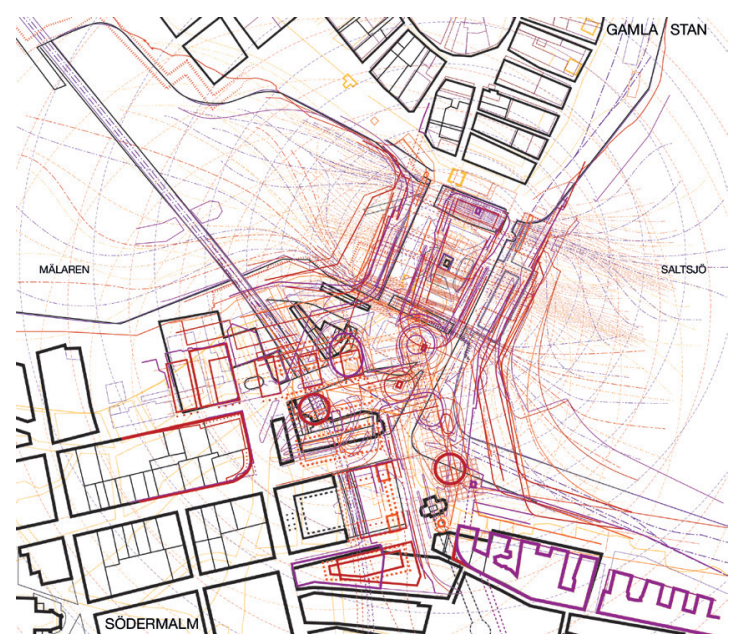

Figure 4. Slussen as a palimpsest. Overlapping of the different spatial configurations of the Slussen (1550, $1700,1770,1850)$ and the sequence of projects by Tage William-Olsson designed between 1929 and 1931 Created by the author, 2017.

complex palimpsest might be observed even after the functionalist project started by Tage William-Olsson and Gösta Lundborg in 1931. This project included as well some historical features of that place: the position and value of the sculpture of Karl Johan XIV and Katarinahissen, the idea of the original isthmus by using a complex "terrain artificiel", the presence of the old Södretorn interpreted by the building Kolingsborg some years later (1954), and, above all, the incorporation of Södra Stadshuset (today Stadsmuseum) in the new masterplan for the area.

However, if we focus on the most recent proposals for the transformation of Slussen in the late two decades and the discussion around the maintenance or destruction of the worn structure of 1935 , it might be relevant to summarize, at least, two different ways of interpreting modern heritage. The first of these readings has been exemplified in "Plan B" (Figure 5), the most coherent and argued alternative to 


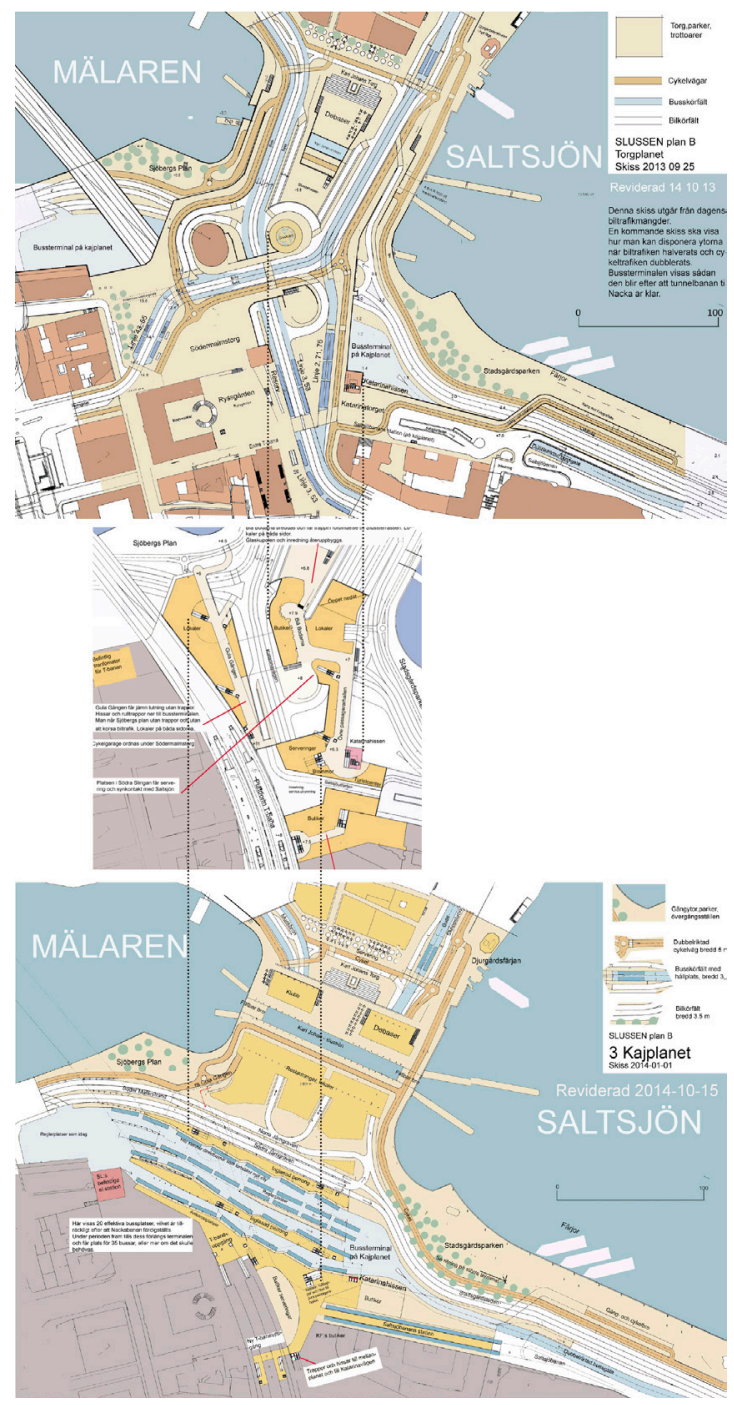

Figure 5. Underground, middle-ground and street surface of the "Plan B" for the Slussen (since 2008). Composition of documents published in http:// slussenplanb.nu

the proposal of Norman Foster+Partners. This proposal, led by an architect, a traffic engineer, an environmentalist and a historian, has been suggesting the demolition and rebuilding of the Slussen of $1935^{6}$. Beyond the discussion around the viability of this proposal (Tingsten, 2011), it is worth highlighting that this project raised the idea of heritage as a preservation of an "image" and prompted the necessary adjustments to fulfil the contemporary functional and environmental requirements, its flexibility and flow easiness. In any case, the unsuccessful impact of "Plan B" shows clearly how difficult is for modern infrastructures to fit in the recycling agenda (Cfr., Alonzo, 2016: 459): they are often too slow to become part of the heritage catalogues but also they should be considered too heavy to be forgotten.

A second approach to the use of modern heritage has been well illustrated by the set of projects developed by Bjarke Ingels Group + NOD since 2006 (Figure 6). Their proposals were very much appreciated by the jury ${ }^{7}$ and,

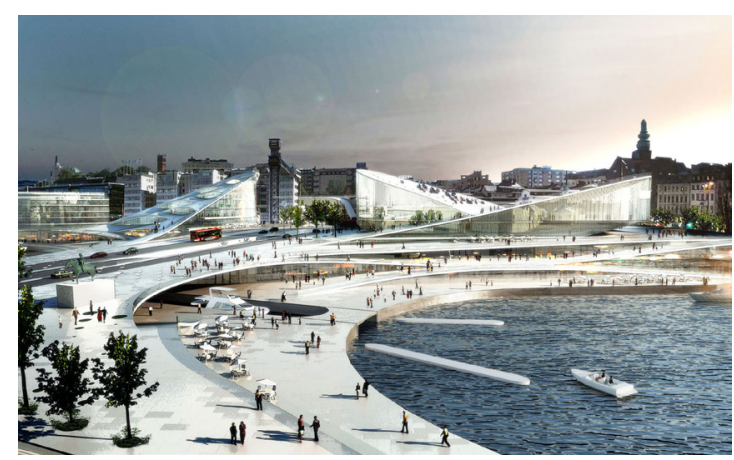

Figure 6. General view of the Slussen proposed by Bjarke Ingels Group+NOD for the international competition in 2008. This is one of the different variations elaborated from 2006 to 2009. https://www.big.dk/\#projects-slu

besides, a number of external reports such as the one written by Spacescape (2008) saw it as one of the best projects among the selected ones ${ }^{8}$.

The first merit of their vision has been precisely the express recognition of the "new Slussen' as an interaction of two perpendicular and equally important force-vectors. As stated in their project report: "Is it possible to keep Slussen as a traffic centre point and, at the same time, turn the site into an (at all levels) urban leisure-zone?"9. With this proposition they assume, then, that new urban interstices like the Slussen should be designed as an integrated mixture of flows and spaces, a confluence of different 'urban things' (De Solà-Morales, 2008), as a place where conflicts might be turned into positive opportunities to produce ambiguity and, therefore, urbanity.

But, above all, their project should be also considered a skilful and contemporary interpretation of Tage William-Olsson's strategies developed for the Slussen in 1935 or, 
to put in other words, a clever understanding of the modern Slussen as a prototype that could be still applied today: "Rather than revolution we are interested in evolution" (BIG, 2010). Their proposal includes, for instance, the use of the inclined surface as an expression of the natural isthmus that configures this place. They have been also developing a complex and wise display of the "function oblique" (Parent, 2009) as an effective mechanism to interweave different levels and overcome the difference in height between the water features and the higher streets of Södermalm. Furthermore, the project has envisaged a contemporary review of the idea of underground passageways tested in the historical Blå Bodarna, Gula Gangen and Gröna Gangen (Clua, 2017), now providing them with more legibility, better materiality, mixed commercial uses and improved accessibility. The architecture for the 'new Slussen' has been also a major discussion and, after more than a hundred of alternatives, their final masterplan answered well to the interstitial condition by minimizing the distance between Gamla Stan and Södermalm, by generating a protected square around the Stadsmuseum and, finally, by inducing the production of different 'microspaces'.

\section{Third lesson: the weight of urban culture in the urban decision-making process}

The third consideration that could be briefly drawn from the Slussen evolution during the last two decades is the observation of the particular way in which the 'urban culture' is able to influence the processes of transformation of central urban interstices. By 'urban culture' we should understand here a certain shared collective thought that, using the well-known triad of Henri Lefebvre (1974), is able to influence the "production of space" in their three intertwined meanings: l'espace conçu (mental representation and projection of the space as an abstract entity), l'espace perçu (referring to the physical-sensible space and the conditions of its daily use) and l'espace vécu (space as a lived environment and representation of a particular society). If we focus specifically in the influence on the first one, on the design considerations, how will this 'culture' be manifested in the Slussen latest process of transformation?

In Stockholm, this shared thought has been expressed in the sharp confrontation between the official decision of developing Foster+Partners proposal and, on the other hand, the outbreak of a large number of collective alternative initiatives. As stated by Michele Micheletti $(2016)^{10}$, a number of administrative changes in Stockholm led to this social manifestation specially focused on the Slussen area: the sequence of up to three different political parties between 1994 and 2014, the increase on political jurisdiction in urban planning (Malmsten and Norberg in Micheletti, 2016: 17), the approval of the Planoch byggladen act regarding the participatory process and, above all, the political vision of this project as a key step towards a "worldclass Stockholm".

The different citizen design alternatives raised after the international competition in 2008 , as a response to the lack of transparency in the management of the process, to the low confidence in the technical solution of the approved project or, as we have state in the previous chapter, as a defense for the Slussen modern heritage. Most of those alternative proposals were supported by architects, engineers, politicians, artists, historians and people involved in urban management processes. Beyond the 1200 letters of protest against the approved 'new Slussen'"1, the more exploratory visions of Måns Tham, Fredrik Falk or Per Gantelius, there have been other proposals of superior technical accuracy: "Ny Syn på Slussen", "Rädda Slussen", "Knutpunkt", "Utblick Slussen" or the aforementioned "Plan B". Some of them were eventually considered in some official reports like the one following the international competition in 2008 but, all in all, their impact in the final resolutions has been very low.

As a consequence of the upheaval of discussions concerning the eventual demolition of the Slussen 1935, the City Hall of Stockholm itself and other private organizations have been promoting a number of monographs and researches on the issue. It is worth mentioning, for instance, the 
exhaustive reading of the evolution by $\mathrm{L}$. Blomquist in Slussens planeringshistoria, (Stadsbyggnadskontoret, 1999); the two volumes about the more general modernization of Stockholm by A. Gullberg in City-drömmen om ett nytt hjärta. Moderniseringen av det centrala Stockholm (Stockholmia, 2001), or the complete approach to the figure and work of Tage William-Olsson. Stridbar planerare och visionär arkitekt (Stockholmia, 2004) by E. Rudberg, B. Bergman, C. Caldenby, A. Gullberg and A. William-Olsson. In Stockholm. En utopisk historia (Prisma, 2004), Åke Abrahamsson has produced a complete review of the unbuilt utopias for Stockholm, with a special mention to some of the ideas for Slussen and Tegelbacken of Tage WilliamOlsson. The Samfundet S:t Erik has been responsible for the publication of the Årsbok 2004 edited by Ulf Sörenson, a gathering of historical, critical and poetical articles on the Slussen (Slussen vid Söderström, Lind \& Co/Samfundet S:t Erik, 2004). Another artfocused and historical vision has been recently exhibited and edited by Eriksson and Sydhoff in 2012 with the title Slussen. När Stockholm var modernt (Konstakademien, Stockholm). And last but not least, an exhaustive description has been commissioned by the Stockholms Stadsmuseum to Maria Lorentzi y Per Olgarsson to register the status quo of the structure of the Slussen in 1935 (Slussen. 1935 års anläggning, Stockholms Stadsmuseum, 2005).

But it is worth mentioning that, among this wide range of publications and interventions, there have been some active groups like YIMBY (Yes In My Back Yard, with $\mathrm{H}$. Tingsten already mentioned), bloggers like Göran Johanson ${ }^{12}$, architects like Jan Söderlund (Cfr. Söderlund, 2004: 167) or companies like the aforementioned Spacescape (directed by L. Marcus and A. Ståhle) that have been engaged into the quick and effective transformation of the Slussen and, sometimes, developing criticism against the most 'nostalgic', 'romantic' or 'proper of a cultural elite' alternative proposals.

In any case, this intense atmosphere of proposals has resulted into the final demolition of the Slussen of Tage William-Olsson as approved in January 2015. The reason for the disregard of the alternatives might be found, as Michele Micheletti pointed out, in the fact that those designs were seen as partial, unconnected to each other and, therefore, not enough powerful to face the official solution.

As a consequence of those reasons, we could note two more remarks. The first one is the consideration of time as a political decision strategy, in other words, the disregard towards citizen involvement in the Slussen renewal process has been eventually minimized by the political 'urgent' need to achieve a definitive solution in a short period of time. Time - even more than technical discussions- is often the definite argument in urban decision-making.

Secondly, the fact is that the final political resolution should be understood as a clear consequence of a sequence of decisions coming from long time ago. A thorough analysis of the proposals surprisingly shows how the current version for the 'new Slussen' is nothing else but a clear evolution of the idea by Leif Blomquist in 1995, a member of the advisory team in the competition held in 2003 and person in charge of the Slussen transformation for many years in the Stadsbyggnadskontoret. That illustrates well the persistence of strong ideas over time and its power to influence any future decision.

\section{Conclusions: towards a smart design of central urban interstices}

After this trip around the spatial configuration, uses, temporalities, ideas and processes that has been operating in the Slussen renewal and, more generally, in central urban interstices, it could be concluded that the so-called 'interstitial condition' prompts a precise and strong character to those urban sites. It has been revealed as a condition that influences inexorably the history of the place, its design, the city and relationships between interstices and their temporal dynamics. Central urban interstices thus become real living records of the city's changes and, because of their double peripheral and central condition, might be regarded as potential new centralities for cities and a key resource to drive a renewed urban structural thinking.

In terms of design strategies, it seems clear 
that the articulation projects on interstitial places shouldn't be addressed as a simplistic extension of the logics of their surroundings but as a place itself, with a unique global and local interescalarity. Because of their spatial and use configuration, those projects should intertwine the infrastructural and metropolitan approach with the counterbalance of the neighbourhood's particularities. Or, to put it in another way, those spaces should be considered both as key mobility hub but also as places with identity: from the "non-lieux" of Marc Augé (1992) to the aforementioned doublelocality of Carsten Juel-Christiansen (1984).

Furthermore, if we focus specifically on the discussion about the value of the heritage of Slussen of 1935, we could end assuring that, as shown by BIG+NOD's proposals between 2006 and 2009, the 'prototype' of Slussen of Tage William-Olsson could be still interpreted in a contemporary way. The use of an inclined topographical surface, the intertwining of shopping stores and facilities underneath, the interaction with the underground or the use of architectures to frame the void are some of the lessons offered by the prototypeSlussen in 1935. Those are indeed some of the key arguments that the final proposal by Foster+Partners have forgotten.

Conversely, the "Plan B" illustrates well the difficulties and paradoxes that a demolition and imitation of the original structure could have in terms of the real value of the heritage and its capacity to deal with new functional requirements. As stated by F. Choay (1992), the "maintenance costs" of heritage, its "unsuitability to current uses" or the capacity to "block the development of larger urban projects" could be seen as the reasons why the Slussen of 1935 has been definitely neglected. In this sense, Plan B might be considered not only a discussion on the idea of copy and authenticity but, above all, on the flexibility or adaptability as an inherent attribute of urbanity in interstitial places (Cfr., Olsson et al., 2015). Are the slight improvements suggested by "Plan B" for the former geometry enough to tackle with the new uses and requirements in a long-term perspective?

Regarding the bustling atmosphere of proposals and alternatives generated in the last two decades on the Slussen, it seems clear that time and inertia have become two decisive points in the process of political decisions. The first one might be observed in the conscious ruin of the concrete structure during the last decades ${ }^{13}$ and in the disregard for the alternatives projects. The inertia, in turn, has been present in the transformation of some old design ideas into strong prejudices in the project of the 'new Slussen'. The ideas are often more definitive than the built constructions.

On the other hand, it should be pointed out how the presence of a growing urban culture has turned out to be definitive in the claim for "more public space" in the Slussen. As shown both in the diagrams by BIG or in the bright renders by Foster+Partners, the contemporary Slussen is called to change its modern celebration of the vehicular traffic into a more human-focused public space priority. Nonetheless, a deep understanding of the Slussen 1935 might also suggests the design of a non specialized public-space platform such as the one proposed in the 'new Slussen'. Public space in central urban interstices should be displayed as an intense relationship with other uses and flows: an 'integrated segregation'. The inherent contradiction between movement and friction should lead to new forms of public spaces, on the basis of the questioning of the efficiency as such and the understanding of the mobility as a contemporary reason to foster encounters and interaction.

Finally, this brief analysis of the Slussen and, hence, other central interstitial places might be useful to point out how those spaces are indeed exceptional registers of the evolution of the city itself. From defence to trade, from commerce to transport, from mobility to public space. They must be recognized as opportune spaces where to build new urban centralities, where to test new forms of intense and adaptive urbanity. Indeed, those spaces might be considered as strategic areas to strengthen the open structure in our cities, a privileged and dynamic field of action for the contemporary urban project and, therefore, an effective way to achieve a more coherent and inclusive city. 


\section{Notes}

${ }^{1}$ This paper summarizes some of the arguments developed in the $\mathrm{PhD}$ thesis written by the author in 2017: La condición intersticial en los proyectos de articulación urbana. Del Slussen al Estocolmo de Tage William-Olsson en cuatro tiempos (Departament d'Urbanisme i Ordenació del Territori, Universitat Politècnica de Catalunya, Barcelona).

${ }^{2}$ See, for example, the article in Svenska Dagbladet, 20th June 2011 or the post "Stoppa Nya Slussen del 2 - Avslöjandet" published on 20th August 2014 in Stockholm Skyline blog.

3 The image of the "bastion" mentioned by Carsten Juel-Christiansen (1985: 70) is very suitable to express the strong duality between 'rupture' and 'transition' that shape central urban interstices.

${ }^{4}$ Title of the book published in 1972 by Kevin Lynch where he draws a complete analysis of the perception and evolution over time of the urban processes, with particular attention to the idea of "adaptability". See Lynch, K. (1972) What time is this place? (Boston: MIT Press).

${ }^{5}$ As stated by Le Corbusier in a note written on the plan of the project given by Tage William-Olsson to him in 1932. Foundation Le Corbusier, 13317.

${ }^{6}$ This idea have many similarities with the one by White Architects in 2007.

${ }^{7}$ The fact that the project of BIG+NOD was further developed after the 2008 competition, might support the hypothesis that the jury was initially supporting their proposal. This has been confirmed in an interview held with the members of the company in 8th June 2016. Nonetheless, the political decision of May 2009 will settle the issue in favour of Foster + Partners and Berg Arkitektkontor.

${ }^{8}$ This report gives a detailed comparison of the five projects submitted for the international competition in 2008. The analysis will use space syntax, place syntax and sociotop methodologies to test the different scenarios for the 'new Slussen'.
${ }^{9}$ Project report on 1st December of 2006, p. 6.

${ }^{10}$ It is highly recommended the reading of the paper by Michele Micheletti where she gives an exhaustive reading on the citizen engagement and political process of the transformation of the 'new Slussen'.

${ }^{11}$ Article of Lars Epstein at Dagens Nyheter, 9th September 2010: "Senaste Slussenförslaget förskräckte kulturborgarrådet". Available at http://blogg.dn.se/epstein/2010/09/09/ senaste-slussenforslaget-forskracktekulturborgarradet-8013/

${ }^{12}$ See the blog Fredman på Kvarnberget by architect and urban planner Göran Johanson at: http://fredmanpakvarnberget.blogspot.com.es/ search/label/Slussen

${ }^{13}$ As stated by Tor Edsjö in an interview held in 11th May 2016. This is a common point claimed by the opponents to the approved "new Slussen".

\section{References}

Abrahamsson, Å. (2004) 'Kristinaslussen' in Sörenson, U. (ed.) Slussen vid Söderstrom (Uppsala, Lind \& Co/Samfundet S:t Erik) 22-31.

Alonzo, É. (2013) 'L'architecture de la voie: histoire et théories', $\mathrm{PhD}$ Tesis, Université Paris-Est, France.

Blomquist, L. (1999) Slussens planeringshistoria (Stadsbyggnadskontoret, Stockholm)

BIG, Bjarke Ingels Group (2010) Yes is more: an archicomic on architectural evolution (Evergreen, Köln).

Clua, Á. (2015) 'Slussen as a paradigm: architecture and infrastructure in five stages', Proyecto, progreso y arquitectura 13, 28-43.

- (2017). 'Underground urbanity: from the carrefour à étages multiples to the "inner street', VLC arquitectura. Research Journal, 4 (1), 61-95.

Corboz, A. (2001) Le territoire comme 
palimpseste et autres essais (Les Éditions de L'Imprimeur, Paris).

Eriksson, E. and Sydhoff, B. (2012) Slussen. När Stockholm var modernt (Konstakademien, Stockholm)

Juel-Christiansen, C. (1985) Monument and niche. The architecture of the new city (Rhodos, København).

- (ed.) (2000) Transitions. Space in the dispersed city (The Architectural Magazine, København).

Lefebvre, H. (1974) 'La production de l'espace', L'homme et la societé, 31(1), $15-32$.

- (2004) Rhythmanalysis. Space, time and everyday life (Continuum, New York).

Lynch, K. and Southworth, M. (1990) Wasting away (Sierra Club Books, San Francisco).

Lynch, K. (1972) What time is this place? (MIT Press, Boston).

Malmsten, B. and Norberg, L. (2014) Politiskt ledarskap i Stockholms stadshus (Stockholmia, Stockholm)

Marcus, L.; Ståhle, A. and Dahlhielm, M. (2010) 'Architectural knowledge and complex urban space. Analysis of five proposals for Slussen in Stockholm', The Journal of Space Syntax, 1 (July), 254-257.

Micheletti, M. (2016) 'Samhällsplaneringens demokratiska utmaning. Samspelet mellan medborgare och staden i förnyelseprojekt som ombyggnaden av Slussenområdet', Statsvetenskaplig tidskrift (in press).

Olsson, M.; Lorentzi, S.; Thune-Hedström, R. and Wiman, C. (2015) Granskning av projekt Slussen Rapport från expertgruppen (Stockholms Stad, Stockholm).

Parcerisa, J. and Crosas, C. (eds.) (2013) Barcelona Enllaços/Links/Enlaces (Laboratori d'Urbanisme de Barcelona, Barcelona).

Parcerisa, J. (2012) Forma urbis: cinco ciudades bajo sospecha (Laboratori d'Urbanisme de Barcelona, Barcelona).

Rudberg, E. and Bergman, B.; Caldenby, C.; Gullberg, A. (2004) Tage William-Olsson. Stridbar planerare och visionär arkitekt (Stockholmia, Stockholm).

Sörenson, U. (ed.) (2004) Slussen vid Söderström (Uppsala, Lind \& Co/Samfundet S:t Erik).
Söderlund, K. and Hjulhammar, M. (2007) Slussen. Stockholms Stad, Slussen Med Angränsande Vattenområden, RAÄ 103 (Stockholms Stadsmuseum och Statens Maritima Museer, Stockholm).

Spacescape (2008) Slussen. Stadslivanalys av fem förslag (Spacescape, Stockholm). 